\title{
7
}

\section{Potential contributions of management science to expert information systems in schools}

\author{
R.G. Taylor \\ North Carolina State University \\ Campus Box 7801, NCSU, Raleigh, NC 28695, USA \\ Phone: 919-745-5544 Fax: 919-745-5771 \\ e-mail:nidrgt2@unity.ncsu.edu
}

\begin{abstract}
In this paper the author claims that a mature expert information system within educational management must incorporate the contributions of management science completely within the information system and transparent to the user/manager. Only by such a complete incorporation can the manager have the benefit of sophisticated underlying mathematical models in the analysis of data without first having to become well-schooled in the mathematics or fully aware of the questions that need to be asked. The marriage between management science and expert systems can thus allow the manager to concentrate on the problems of pedagogy, knowing that the information system will "automatically" provide the information he/she needs to make good decisions.
\end{abstract}

Keywords

Management information systems, operations research, expert systems

\section{INTRODUCTION}

Management science uses a group of mathematically-oriented methods to help managers make good decisions. These methods apply to two large categories of problems. The first pertains to optimization, wherein, limited resources must be allocated in such a way as to maximize or minimize one or more specified objectives. The second pertains to the reduction of risk and uncertainty -- making the best decision when some or all of the information needed for that decision is probabilistic. Management science is now welldeveloped and is widely used in business, industry and banking, as well as in certain large public-sector agencies such as the military. It is less often employed in state and 
regional governmental agencies and almost never in the management of educational systems. The few examples of management science in education which appeared in the literature from 1968 to the early 90 s have been documented, commented upon, and expanded by Taylor (1992).

The present author has been involved in teaching management science in education through workshops, lectures, and publications since 1985 and has observed some of the reasons why management science has not claimed the attention of educational administrators. First, it is inherently mathematical, and most school administrators are not well schooled in the mathematics. Although classical inferential statistics is often included in the training of educators, the standard mathematical tools upon which management science are based are generally omitted -- linear algebra, linear programming, calculus, and topics in statistics such as stochastic processes. Secondly, until recently, management science models were solved using mainframe computers -- a tool that was generally unavailable or not easily mastered by those in educational decision-making roles.

\section{EMERGING POSSIBILITIES}

Notwithstanding these historic constraints to the advancement of management science in education, the science and its underlying computer hardware technology are on the edge of a breakthrough that could substantially improve the rate of adoption and the utility of the tools for educational administrators. More specifically, the capacity of microcomputers to solve full-sized realistic management science problems is now available and inexpensive, as are robust computer programs designed to handle such problems without fully involving their users in the underlying mathematical complications. Even more importantly, the growing interest in decision support systems and expert systems within educational management, suggests a marriage between management science and decision support which could be far more beneficial than either set of tools used alone.

The remainder of this paper makes a case for having certain management science models "live within the bowels" of the decision support system, constantly updating themselves and yielding information that the educational manager needs but may not have the prerequisite skills or awareness to ask for. Readers who are familiar with expert systems and exception reporting may well regard the suggestions made here as a mere elaboration on what has been promulgated by others. Similarly, readers who are familiar with the tools of management science may well conclude that the suggestions made here are elementary or obvious. What both readers need to appreciate is that the technologies of management science and expert systems have not been integrated within the field of educational management, and that both technologies have limitations that the other can remove.

\section{EXAMPLES}

Consider an example recently studied by a doctoral student at North Carolina State University. Working within an industrial education environment, she built a Markov model based on how trainees moved through the skill levels of a certain Computer Assisted Instruction (CAI) module. There were, perhaps, eight skill levels, seven needed for certification. Every so many minutes, a snapshot was taken within the CAI system. The snapshot updated the Markov matrix (probability of moving from any one skill level to any other). After enough persons had been through the CAI module, 
several analytical possibilities emerged. The instructor could make optimal interventions, because s/he would know who was functioning at or below any given percentile in terms of past (normative) performance. S/he could also tell, based on the first passage time analysis within the model, how long it would be before some given percentage of the total group would reach mastery. Or, put differently, s/he could tell how much longer the present group would have to work before 80 percent of the machines would be available to a new group.

The above illustration is heavy on the management science side of the marriage. Now, let us suppose that the instructor or CAI systems manager were not required to make any of the inquiries suggested above, but that the Markov system was automatically created and updated for every CAI module. And, further, that a small electronic alarm would tell the instructor (on the instructor's screen) that the person at machine 14 was well outside the band of normative performance and needed help. And let us suppose that every halfhour a forecast for the group and a forecast for the future availability of the resource was made and a suggested schedule for the next group was produced. These auto-reporting mechanisms could occur without the CAI manager knowing any of the underlying mathematics or without even knowing that s/he should seek such information.

Consider one more illustration based on an entirely different management science model. In many cities in the United States, there is, either voluntarily or as a result of court intervention, an effort to racially balance the enrollments within public schools. This is done by creating attendance boundaries that capture, for each school, a certain proportion of children from each pertinent race. The goal is to have the balance within each school similar to the balance within the overall system. Some students and their parents resist such assignments by changing their place of residence. Thus, "flight" and other demographic phenomena require that attendance lines need to be periodically changed. The danger is that one or more schools will get too far out of balance before administrators are aware of what is happening. If the system is under a court decree, such imbalance can cause considerable economic and political problems for the administration, as well as a sudden disruption in the educational program of children who must change schools with little notice.

Now, let us suppose that the transportation information system (a GIS [Geographic Information System]-based system used in many school systems which can convert addresses to X-Y coordinates as well as performing many routing and scheduling functions) and the student information system (which includes race and address) were automatically linked together along with a forecasting model. The model would make forecasts based on small areas within the system's perimeter, monitoring and projecting numbers of students and their racial composition. As these small areas change demographically, a forecast for the schools to which those areas are assigned could likewise be forecast and could yield warning that certain schools would, within one year, be beyond a tolerable balance. A binary linear program could then annually find the optimal assignment of areas to schools, balancing race and minimizing distance. In April or May of each year, the system would automatically report recommended changes in boundaries for the coming fall. Again, the underlying mathematics would not need to be understood by the user, nor would the user have to ask all the right questions in order to receive the recommendation.

\section{SUGGESTIONS FOR FUTURE DIRECTION}

There are countless possible examples of how management science and decision support systems could inform each other and exponentially increase their respective values for school administrators. A very brief description of each of several possibilities follows: 


\section{Contributions of management science to expert information systems 55}

- Merit pay systems could employ linear programming to make an optimal distribution of funds. In such a system, the objective would be to maximize the amount of salary money awarded to each teacher for performance on each merit compensation variable, subject to all the constraints of the employing institution and the agreement between the employer and employees. Such variables might include teaching performance, professional development activities, school citizenship, extra duties, and so on. The constraints would include merit money available, and limits on the amount of merit pay that can be obtained by any one teacher.

- Systems for the analysis of impending teacher shortages could use Markov analysis, a well-known tool within the world of engineering. Markov analysis helps managers understand the behavior of dynamic systems, in which the elements being studied are constantly in the process of changing states. In terms of the teacher shortage problem, those states might include: a) being enrolled in a teacher training program in a particular field, b) being a first year teacher in that field, c) continuing beyond the first year, d) taking an unpaid leave from teaching, and so on. By tracking the movement of individuals once every year with respect to these states, an overall understanding of the way teachers move through career paths can be determined. This determination yields answers to many policy questions and, in addition, allows the school manager to gauge impending shortages.

- General scheduling problems (rooms, teachers, courses, times of day) can, if the scale is small enough, use binary programming, or for large scale scheduling problems, some sort of matrix/conflict system. In any case, much of the work commonly associated with the use of these methods could be automated within the management information system so that annual or semi-annual schedule-building would not be daunting.

- One of the critical problems in scheduling, especially in higher education, is finding an optimal sequence of teachers for given students. Based on the absence of any indication in the commonly available literature, the present author believes that this problem has never been studied or controlled scientifically. As an example, consider what happens in a large university that specializes in engineering. Students might be expected to take a sequence of four mathematics courses during their freshman and sophomore years. Now, for the best students, this sequence presents no serious threat. Such students will earn high grades regardless of which combination of instructors they draw. At the other extreme, the poorest students are likely to have difficulty passing even the first course. For the large majority of students, however, how the courses are taught will make a big difference in how well they perform. A student who was able to earn a low " $\mathrm{B}$ " in the first course from an instructor who used many examples and graphic illustrations, might have great difficulty if, in the second course, he is scheduled with an instructor who uses only abstract mathematical symbolization. Since there are many possible approaches to the subject and many teaching styles, the dozens of sections of each course that are available each semester are not truly interchangeable. Instead, there are combinations of instructors that provide a "best path" through the four courses for each student. Instead of letting students register for sections without "intelligence," it would maximize overall success for students and productivity for the university to compute the best paths based on what is known about the student or based on his/her success or failure in the first course or two. This is a classic dynamic programming problem, with well-documented parallels in industrial job-shop optimization.

- Enrollment projections have long relied on the cohort survival method of forecasting. Recent elaborations of this model have made such forecasts even more accurate. Since the method and its improvements rely on annual grade-by-grade data, and such data should be easily available from the student information system, such forecasts should be provided automatically. 
- The use of nonlinear programming for finding the optimal locations for new schools in growing school systems was impractical until recently. Now, however, the presence of powerful nonlinear solvers for PCs has made the use of this tool very cost efficient. By properly sizing and placing new facilities, substantial reductions in long-term transportation costs can be achieved. This is especially true when such problems are constrained by racial or other social balance requirements as in the United States.

- There are many policy analyses issues that can best be studied using management science techniques. For example, it is impractical to determine the outcome of certain facility or transportation policies by experimentation. The school system cannot build multiple structures or set up multiple transportation networks just to see which works best. Likewise, it may be immoral to study other policies by experimentation. Can a system in good conscience try several different personnel management policies (such as retirement rules) just to see which works best? By simulating the physical or social environment on the computer, many such policies can be tested without dire consequence. In other cases, instead of simulations, it may be possible to compute the probabilistic outcome of each policy alternative using Bayesian analysis. In the literature there are a few examples in which this approach was successfully employed.

In all of these cases, the tools are unlikely to be widely used if they retain their present status as stand-alone management science methods. Educational managers simply do not have the time, and in many cases do not have the skills, to use precise mathematical methods to inform their practice. However, if the information scientists were to use the same tools deep within the structure of the Management Information System and make them transparent to the user, then such systems would take on an "expert systems" quality and would yield extremely useful results.

Information Technology in Educational Management for the 21st Century will be missing a major opportunity unless the marriage between management science and information systems is encouraged.

\section{REFERENCES}

Taylor, R. (1992) Decision science in the public sector: emphasis on applications to educational administration. Felicity Press, North Whitefield, ME, USA.

\section{BIOGRAPHY}

Prof. Raymond G. Taylor is the president of OR/Ed Laboratories and professor of educational administration at North Carolina State University. $\mathrm{He}$ also holds appointments as an associate faculty member in Operations Research at NCSU and as a visiting associate to the Moscow Institute of Economics, Politics and Law. 